\title{
Characterization of isolated fractions of dissolved organic matter from sewage treatment plant and the related disinfection by-products formation potential
}

\author{
Hua Zhang a,b, Jiuhui Qu ${ }^{\mathrm{a}, *}$, Huijuan Liu ${ }^{\mathrm{a}}, \mathrm{Xu}^{\mathrm{Z}} \mathrm{Zhao}^{\mathrm{a}}$ \\ a State key Laboratory of Environmental Aquatic Chemistry, Research Center for Eco-Environmental Sciences, Chinese Academy of Sciences, Beijing 100085, China
}

${ }^{\mathrm{b}}$ Graduate School, Chinese Academy of Sciences, Beijing, China

\section{A R T I C L E I N F O}

\section{Article history:}

Received 11 January 2008

Received in revised form 13 August 2008

Accepted 16 September 2008

Available online 25 September 2008

\section{Keywords:}

Dissolved organic matter

Fractions

Chlorination

Disinfection by-products

Chemical characteristics

\begin{abstract}
A B S T R A C T
Dissolved organic matter (DOM) in effluent from a conventional sewage treatment plant was isolated using resin adsorbents into six classes: hydrophobic bases (HoB), hydrophobic acids (HoA) and hydrophobic neutrals ( $\mathrm{HoN}$ ); hydrophilic bases ( $\mathrm{HiB})$, hydrophilic acids (HiA) and hydrophilic neutrals (HiN). Organic acids were the most abundant fractions of DOM. Hydrophobic organics especially hydrophobic acids were found to have higher overall disinfection by-products formation potential (DBPFP). Moreover, the potential decreased as the sequence of acids, neutrals and bases. Ultraviolet spectrophotometry at $254 \mathrm{~nm}\left(\mathrm{UV}_{254}\right)$, fluorescence spectroscopy, size exclusion chromatography and Fourier transform infrared spectroscopy (FTIR) were employed to characterize DOM fractions. And the relationship between the characteristics of DOM fractions and the related DBPFP was discussed in detail. It was found that $\mathrm{UV}_{254}$ to DOC ratio (SUVA) exhibited a positive correlation with haloacetic acids (HAAs) formation potential whereas distinctive linear correlation was not observed between SUVA and trihalomethanes (THMs) formation potential. Of the fluorescence organics contained in DOM, humic acids exhibited higher chlorine reactivity than fulvic acids. Smaller molecules of humic acids produced more DBPs. Furthermore, a combination of aromatic moieties and aliphatic structures with $v(\mathrm{C}-\mathrm{O})$ groups contributed largely to the formation of DBPs.
\end{abstract}

(C) 2008 Elsevier B.V. All rights reserved.

\section{Introduction}

Wastewater reuse is increasingly regarded as a potential water resource for substantial reduction in water supply needs and savings in related costs [1-3]. However, the wide implementation of actual reuse depends, to a larger extent, on the safety of recycled wastewater [4]. Most sewage treatment plants (STPs) receive complex mixtures of urban and industrialized discharges. Even after secondary treatment, they still contain a large amount of dissolved organic matter (DOM), which serves as a precursor in the chlorination process to the formation of potentially harmful disinfection by-products (DBPs) such as trihalomethanes (THMs) and haloacetic acids (HAAs) $[5,6]$.

Previous research has studied the influences of temperature, $\mathrm{pH}$, reaction time, chlorine concentration, as well as the concentration of DOM on the formation of DBPs [7,8]. However, the chemical characteristics of DOM are thought to influence the chlorine consumption and the formation of DBPs largely. Sirivedhin and Gray [9] found a combination of aromatic and aliphatic structures including some substituted with nitrogen and chlorine to show a linear rela-

\footnotetext{
* Corresponding author. Tel.: +86 10 62849151; fax: +861062923558.

E-mail addresses: jhqu@rcees.ac.cn, jhqu@mail.rcees.ac.cn (J. Qu).
}

tionship with DBPs formation potential (DBPFP). Leenheer et al. [10] demonstrated that phenol structures produced significant DBPs and that aromatic sulfonates and fulvic acids in reclaimed water contributed to minimal DBPs. However, different water source may lead to different results; thus, more studies are in great need to understand the effect of characteristics of DOM on the formation of DBPs.

The water samples in this study were taken from Gaobeidian sewage treatment plant (STP). It was withdrawn from the effluent after the sand-filtration and before the chlorination process. Gaobeidian STP is the largest in China and has been making great efforts to construct one of the biggest projects in China for wastewater reuse. The project for wastewater reuse plays an important role in reducing water stress of China, in particular Beijing, the host city of 2008 Olympic Games. DOM from Gaobeidian STP is composed of recalcitrant natural organic matter (NOM) from drinking water, synthetic organic chemicals added during anthropogenic use and soluble microbial products [11,12].

Historically, Leenheer et al. [10] used resin adsorption chromatography (RAC) technique to fractionate DOM of tertiary-treated municipal wastewater into hydrophobic acids, hydrophobic neutrals, hydrophilic acids, colloidal hydrophilic neutrals and dissolved hydrophilic neutrals. Imai et al. [13] modified the DOM fractionation method developed by Leenheer [14] and isolated DOM in 
effluents from sewage and human-wastes treatment plants into six classes. With the application of RAC, researchers have found out some characteristics of DOM from wastewater. However, the relationship between characteristics and DBPFP of different DOM fractions has long lacked further analysis.

In this study, DOM from Gaobeidian STP was isolated into six classes using RAC technique to examine the chlorine reactivity of DOM. Different analysis methods were used to characterize DOM fractions and the effect of characteristics of DOM fractions on the formation of DBPs was also studied to find out what organics contributed largely to the formation of DBPs. The results of this study will give us some fundamental ideas that which classes of DOM must be removed in the water treatment process to reduce the DBPs formation in the chlorination process.

\section{Materials and methods}

\subsection{Collection of water samples}

Effluent samples were collected from Gaobeidian STP that incorporated activated sludge treatment process and advanced treatment, such as coagulation and sand-filtration. Most of the effluent is used as reuse water without further treatment. Water samples for this study were collected at sand filtration site and filtered immediately through a pre-rinsed $0.45-\mu \mathrm{m}$ cellulose filter and stored in the dark at $4{ }^{\circ} \mathrm{C}$ until analysis.

\subsection{Fractionation and collection of DOM fractions}

The fractionation of DOM was performed following the procedure modified from Imai et al. [13], Leenheer [14] and Chefetz et al. [15]. This fractionation procedure is illustrated in Fig. 1.

$0.45 \mu \mathrm{m}$-filtered reuse water was firstly pumped through a glass column of Amberlite XAD-8 resin (20-60 mesh). Hydrophobic

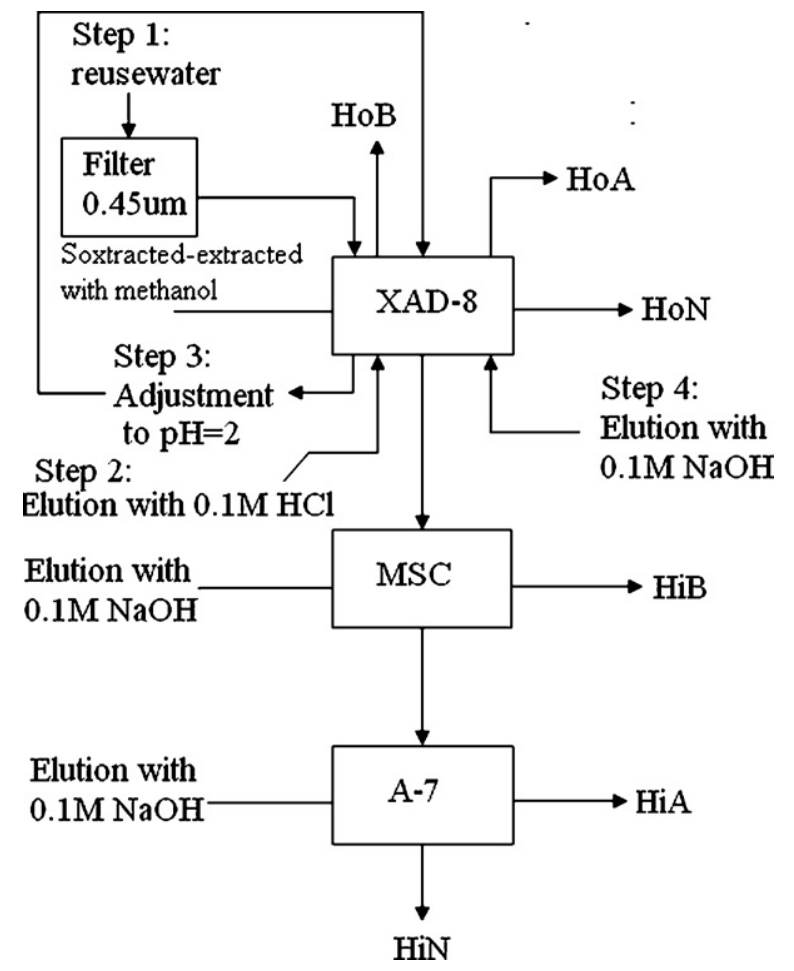

Fig. 1. Schematic diagram of the procedure for DOM fractionation. HoB, hydrophobic bases; HoA, hydrophobic acids; HoN, hydrophobic neutrals; HiB, hydrophilic bases; HiA, hydrophilic acids; HiN, hydrophilic neutrals. bases $(\mathrm{HoB})$ were then desorbed from the resin with $0.1 \mathrm{M} \mathrm{HCl}$. The sample effluent was acidified to $\mathrm{pH} 2$ with $6 \mathrm{M} \mathrm{HCl}$ and cycled over three connected Amberlite XAD-8, Dowex Marathon MSC resin (20-50 mesh) and Duolite A7 (free base), respectively. The effluent from the connected three columns was hydrophilic neutrals (HiN). Hydrophobic acids (HoA), hydrophilic bases (HiB) and hydrophilic acids (HiA) were desorbed from XAD-8, Dowex Marathon MSC and Duolite A7 with $0.1 \mathrm{M} \mathrm{NaOH}$, respectively. After $\mathrm{HoA}$ was desorbed, the XAD- 8 resin was air-dried for about $12 \mathrm{~h}$ and was soxhlet-extracted with methanol to obtain hydrophobic neutrals (HoN). The excess methanol was removed by vacuum-rotary evaporation at $40^{\circ} \mathrm{C}$.

\subsection{Organic carbon analysis}

Dissolved organic carbon (DOC) was measured with a TOC analyzer (Multi N/C 3000) in accordance with Standard Method 5310D. The $\mathrm{UV}_{254}$ to DOC ratio (SUVA) was reported to represent the aromatic characteristic of organic matters as they imparted the ability to absorb light in the UV range [16].

\subsection{Disinfection by-products formation potential (DBPFP) analysis}

In order to compare the characteristics of DOM fractions, all samples were conditioned to similar TOC concentrations above $3 \mathrm{mg} / \mathrm{L}$. A chlorine dose of $20 \mathrm{mg} / \mathrm{L}$ was applied to DOM solutions buffered at $\mathrm{pH}$ 7. Following incubation in the dark for 3 days, the solutions was quenched with sodium sulfite $\left(\mathrm{Na}_{2} \mathrm{SO}_{3}\right)$. THMs and HAAs analyses were conducted using an Agilent 6890N gas chromatograph (USA). THMs, i.e. chloroform, was analyzed in accordance with EPA method 551.1. Two species of HAAs, i.e. dichloroacetic acid (DCAA) and trichloroacetic acid (TCAA), were analyzed in accordance with EPA method 552.3. A series of aqueous DBPs standards was generated by adding a range of volumes of the stock solutions to Milli-Q water. A blank $(0 \mu \mathrm{g} / \mathrm{L}$ as DBPs standards) of Milli-Q water was included in the development of all standards curves. Under the assumption of linear response behavior, regression analyses always yielded $R^{2}>0.99$.

\subsection{Molecular size distribution analysis}

High-pressure size exclusion chromatography (HPSEC) was performed at room temperature with a Hitachi L-2000. Mobile phases were composed of Milli-Q water buffered with phosphate $\left(0.0024 \mathrm{M} \mathrm{NaH}_{2} \mathrm{PO}_{4}+0.0016 \mathrm{M} \mathrm{Na}_{2} \mathrm{HPO}_{4}\right)$ to a pH of 6.8 and $0.01 \mathrm{M}$ sodium acetate $(\mathrm{NaAc})$ to yield an ionic strength of $0.1 \mathrm{M}$. Polystyrenesulfonates standards (PSS) of known molecular weights $(15,650$, 6200,4600 and $1370 \mathrm{Da}$ ) and acetone (58 Da) were used for MW calibration of chromatograms.

Weight-average molecular weight $(M w)$ and number-average molecular weight $(\mathrm{Mn})$ were calculated using the following equations [17]:

$M w=\frac{\sum(h i M i)}{\sum h i}$
$M n=\frac{\sum h i}{\sum h i / M i}$

$M_{i}$ and $h_{i}$ are the molecular weight and the height of each $i$ th fraction eluted at the $i$ th volume in the chromatogram, respectively. 


\subsection{Fourier transform infrared spectroscopy (FTIR) analysis}

DOM powder obtained through freeze-drying the fractions was analyzed for the structural and chemical characteristics of DOM. $\mathrm{KBr}$ was mixed with the DOM powder about the ratio of 100 to 1 and the FTIR spectra of the mixture were obtained by scanning it with FTIR spectrometer (Thermo Nicolet 5700, USA).

\subsection{Fluorescence spectroscopy analysis}

Fluorescence spectra were recorded on a fluorescence spectrophotometer (model F-4500, Hitachi, Japan). Three-dimensional spectra were obtained by measuring the emission spectra in the range from 300 to $550 \mathrm{~nm}$ repeatedly, and at the excitation wavelengths from 230 to $480 \mathrm{~nm}$, at $5 \mathrm{~nm}$ intervals in the excitation domain.

\section{Results and discussion}

\subsection{DOM-fraction distribution and $U V_{254}$ to DOC ratio (SUVA)}

DOC concentration of the reuse water, i.e. effluent after coagulation and sand-filtration, ranged from 7.2 to $8.2 \mathrm{mg} / \mathrm{L}$ and the $\mathrm{UV}_{254}$ to DOC ratio (SUVA) was at $1.5-2.2 \mathrm{~L} / \mathrm{mg} \mathrm{m}$.

DOM fractions of the reuse water exhibited different DOM measured as DOC distribution (Fig. 2a). Hydrophobic organics were the dominant part, collectively accounting for more than $60 \%$ of their
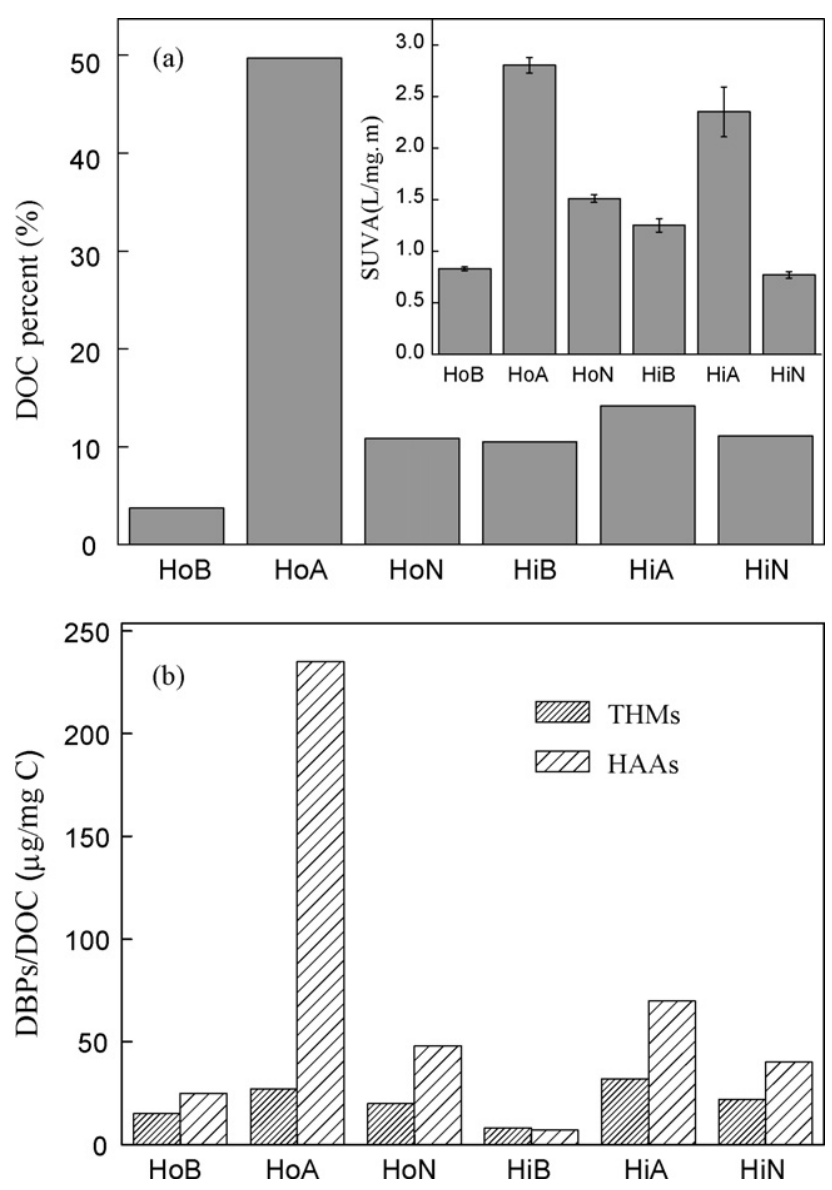

Fig. 2. (a) Percent of DOC and SUVA of DOM fractions from reuse water of Gaobeidian STP. (b) THMs and HAAs formation potential per DOC of DOM fractions. DOM fractions are HoB, hydrophobic bases; HoA, hydrophobic acids; HoN, hydrophobic neutrals; HiB, hydrophilic bases; HiA, hydrophilic acids; HiN, hydrophilic neutrals.
DOM as DOC. In particular, the HoA fraction was found to be the most abundant fraction, constituting about $50 \%$ of DOC. HiA was the second most dominant fraction, accounting for about 15\%. DOM percents of $\mathrm{HoN}$ and $\mathrm{HiN}$ were similar at about $10 \%$. The HoB fraction was the lowest in all the fractions, constituting less than $4 \%$ of DOC

DOM-fraction distribution varied substantially depending on the kind of wastewater and type of treatment process. It was found that HiA in DOM from several effluents in Japan were the dominant fraction ranging $32-74 \%$ of DOM, whereas aquatic humic substances appeared to be the second most abundant fraction, constituting 3-28\% [13]. Wang et al. [18] studied seven effluents in China treated with three kinds of processes, suggesting that effluents treated by activated sludge process contained more hydrophobic fractions than hydrophilic organics.

As shown in Fig. 2a inset, the sequence of these six organic fractions with respect to SUVA was summarized in the order from largest to smallest as: $\mathrm{HoA}>\mathrm{HiA}>\mathrm{HoN}>\mathrm{HiB}>\mathrm{HoB}>\mathrm{HiN}$. Organic acids, HoA and HiA, exhibited the highest SUVA even higher than that of reuse water, whereas the SUVA of HiN was lower than $1 / 2$ SUVA of reuse water. DOM-fraction distribution influenced the SUVA of effluent from sewage treatment plants to some extent.

\subsection{THMs and HAAs formation potential (THMFP and HAAFP) of DOM fractions}

In order to investigate the reactivity with chlorine on a per carbon basis, all the DBPs data were normalized relative to the DOM concentrations to obtain the specific yields.

As shown in Fig. 2b, organic acids, HoA and HiA, exhibited the largest THMFP and HAAFP, respectively. All fractions showed a common relationship with respect to HAAFP: HoA > HiA, $\mathrm{HoN}>\mathrm{HiN}, \mathrm{HoB}>\mathrm{HiB}$; and the potential decreased as the sequence of acids, neutrals and bases. The THMFP of DOM fractions followed the order: $\mathrm{HiA}, \mathrm{HoA}>\mathrm{HiN}, \mathrm{HoN}>\mathrm{HoB}>\mathrm{HiB}$; and the decreasing sequence was similar to that of HAAFP.

Obviously, organic acids exhibited the highest chlorine reactivity, consistent with their highest SUVA. Some researchers thought SUVA indicated aromaticity caused by the presence of unsaturated bonds, i.e. chromophores and aromatic moieties and was reliable to embody DBPFP [19-21]. In this study, HoA and HiA with the highest SUVA possessed maximum DBPFP, which was consistent with previous research. For all DOM fractions, SUVA exhibited a positive and linear correlation with $\operatorname{HAAFP}\left(R^{2}=0.68\right)$, whereas no significant correlation was observed between SUVA and THMFP. The observed relationship between SUVA and DBPFP in our study was not as strong as was reported by Kitis [22], which only investigated the relationship of DBPFP and SUVA of total DOM. DOM fractions were isolated from total DOM according to their different characteristics, thus a different relationship with DBPFP indicated that each DOM fraction had different reaction mechanism during chlorination. Furthermore, HAAFP and THMFP exhibited a different relationship with SUVA suggesting that the formation mechanism of HAAFP and THMFP were different.

\subsection{Effect of source on THMFP and HAAFP of DOM fractions}

Previous studies demonstrated that treated wastewater effluent contained residual DOM present in drinking water, soluble microbial products contributed during biological sludge treatment and refractory DOM added by water users [23]. In order to trace the source of DOM and investigate the chemicals contributing to DBPs, excitation emission matrix (EEM) was used to characterize different DOM fractions. The contour maps of the results showed that different fractions exhibited different peaks (Fig. 3). The 

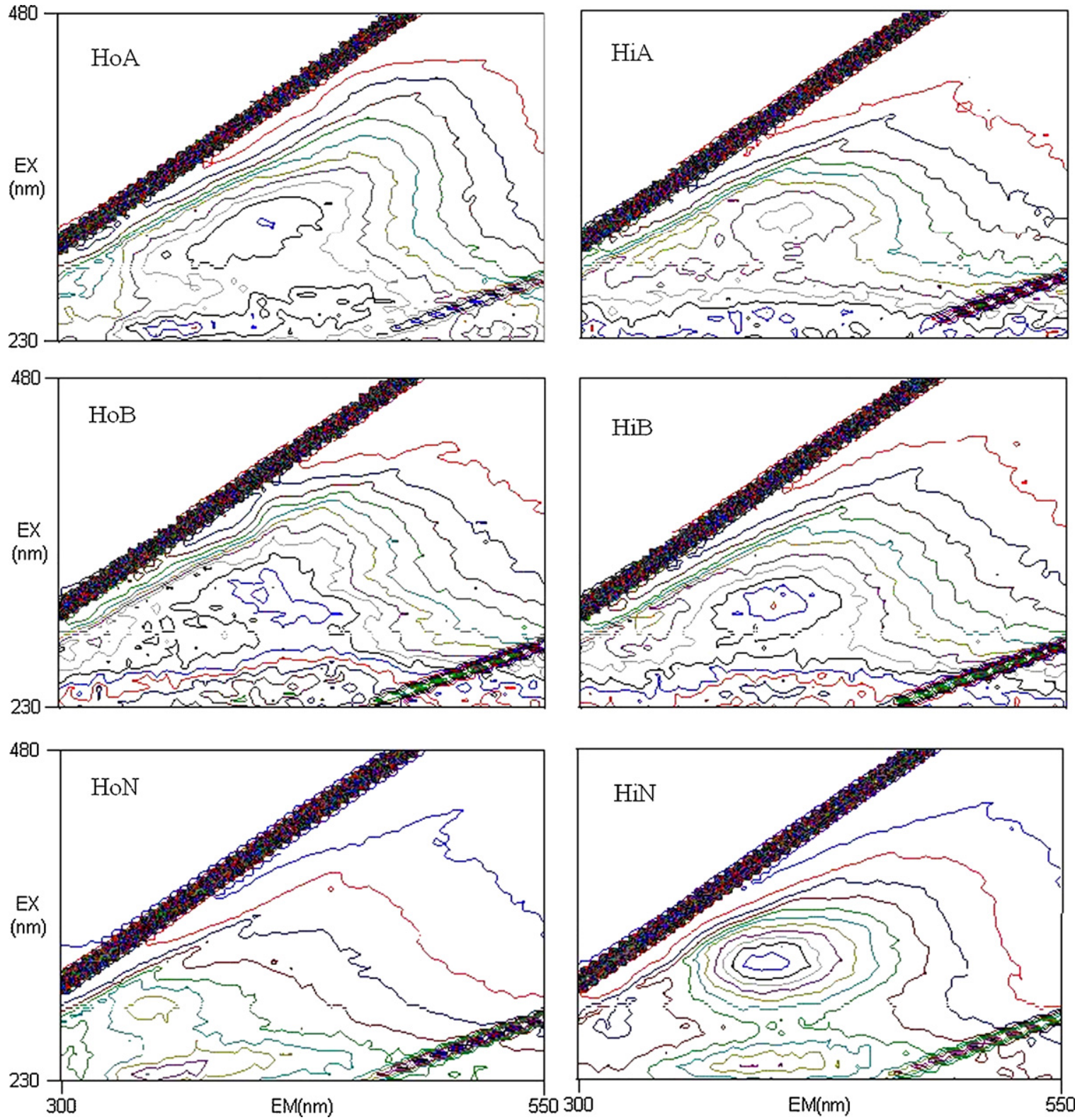

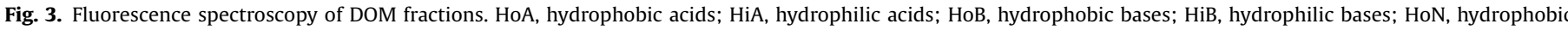
neutrals; HiN, hydrophilic neutrals.

\section{Table 1}

EEM peaks for the DOM fractions.

\begin{tabular}{|c|c|c|c|}
\hline DOM fractions & $\operatorname{Ex} / \operatorname{Em}(\mathrm{nm} / \mathrm{nm})$ & Substances & Intensity (on a per carbon basis) \\
\hline \multirow[t]{2}{*}{$\mathrm{HoA}$} & $316 / 404$ & Marine humic acids & 33 \\
\hline & $239 / 368$ & Aromatic proteins & 36 \\
\hline \multirow[t]{2}{*}{ HoB } & $314 / 404$ & Marine humic acids & 21 \\
\hline & $236 / 394$ & Fulvic acid-like & 30 \\
\hline \multirow[t]{2}{*}{$\mathrm{HoN}$} & $288 / 349$ & Soluble microbial by-product like, protein-like or phenol-like & 21 \\
\hline & $234 / 345$ & Simple aromatic proteins such as tyrosine & 26 \\
\hline \multirow[t]{3}{*}{$\mathrm{HiA}$} & $235 / 410$ & Fulvic acid-like & 22 \\
\hline & $319 / 398$ & Marine humic acids & 19 \\
\hline & $305 / 352$ & Soluble microbial by-product like, protein-like or phenol-like & 13 \\
\hline \multirow[t]{2}{*}{$\mathrm{HiB}$} & $305 / 400$ & Marine humic acids & 24 \\
\hline & $230 / 390$ & Fulvic acid-like & 22 \\
\hline \multirow[t]{2}{*}{$\mathrm{HiN}$} & $317 / 398$ & Marine humic acids & 34 \\
\hline & $240 / 389$ & Fulvic acid-like & 24 \\
\hline
\end{tabular}


Table 2

Molecular weight and polydispersity of DOM fractions.

\begin{tabular}{lccl}
\hline & $\begin{array}{l}\text { Number-averaged } \\
\text { molecular weight }(\mathrm{Mn})\end{array}$ & $\begin{array}{l}\text { Weight-averaged } \\
\text { molecular weight }(\mathrm{Mw})\end{array}$ & $\begin{array}{l}\text { Polydispersity } \\
(\mathrm{Mw} / \mathrm{Mn})\end{array}$ \\
\hline HoB & 830 & 7334 & 8.84 \\
$\mathrm{HoA}$ & 1096 & 2950 & 2.69 \\
$\mathrm{HoN}$ & 1019 & 2234 & 2.19 \\
$\mathrm{HiB}$ & 509 & 1346 & 2.64 \\
$\mathrm{HiA}$ & 2328 & 10,014 & 4.30 \\
$\mathrm{HiN}$ & 299 & 1276 & 4.27 \\
\hline
\end{tabular}

substances and fluorescence intensity corresponding to the peaks are shown in Table 1. Humic/fulvic acids, aromatic proteins and some other soluble microbial by-products such as protein-like or phenol-like organics were found in DOM fractions. Compared with hydrophobic organics, all hydrophilic fractions contained fulviclike acids in addition to humic-like acids, whereas hydrophobic organics contained protein-like organics with the exception of HoB. In particular, HoA exhibited high intensity of aromatic proteins.

As shown in Table 1, HoA and HiN contained marine humic acids with similar intensity, whereas in addition to marine humic acids, HoA contained aromatic proteins and $\mathrm{HiN}$ contained fulvic acids. On the other hand, HoA exhibited much higher DBPFP than HiN. Thus, it can be concluded that the formation of DBPs attributed more to aromatic proteins than to fulvic acids. Compared with organic bases, HiN contained more humic acids than fulvic acids and had higher DBPFP, suggesting that humic acids produced more DBPs than fulvic acids. The intensity of humic/fulvic acids was lower in $\mathrm{HiA}$ than in $\mathrm{HiN}$; however, HiA also contained soluble microbial by-products such as protein-like or phenol-like organics. Therefore, the higher DBPFP of HiA was due to the existence of protein-like or phenol-like organics. In the HoN fraction, humic/fulvic acids were not detected, whereas soluble microbial products and simple aromatic proteins were found.

\subsection{Effect of molecular weight distribution on THMFP and HAAFP of DOM fractions}

The weight-averaged to number-averaged molecular weight ratio (i.e. the polydispersity) of DOM fractions was more than 2 , indicating that the molecules of DOM fractions occupied a relatively broad size fraction and possibly possessed molecular weights that vary by orders of magnitude [13] (Table 2). The numberaveraged molecular weight of DOM fractions was quite different, ranging from 299 to $2328 \mathrm{~g} / \mathrm{mol}$. Organic acids, HoA and $\mathrm{HiA}$, exhibited higher molecular weights. Compared with hydrophobic fractions, hydrophilic organics exhibited low weight-averaged and number-averaged molecular weights with the exception of HiA.

It was found that the molecular weight of DOM fractions was not consistent with SUVA or DBPFP. The observation suggested that DOM fractions exhibited different characteristics with their mixture, i.e. total DOM. Each DOM fraction contained more simple organics than total DOM. Furthermore, DOM fractions exhibited different polydispersity, suggesting different organics contained in each fraction. However, HiA and HoA exhibited higher molecular weight and to some extent this was consistent with the higher DBPFP. Generally, there existed no relationship between molecular weight of DOM fractions and DBPFP. In particular, HiN exhibited the lowest molecular weight and SUVA; however, the DBPFP was higher than that of organic bases. As shown in Table 1, HiN contained relatively more humic acids with high chlorine reactivity.

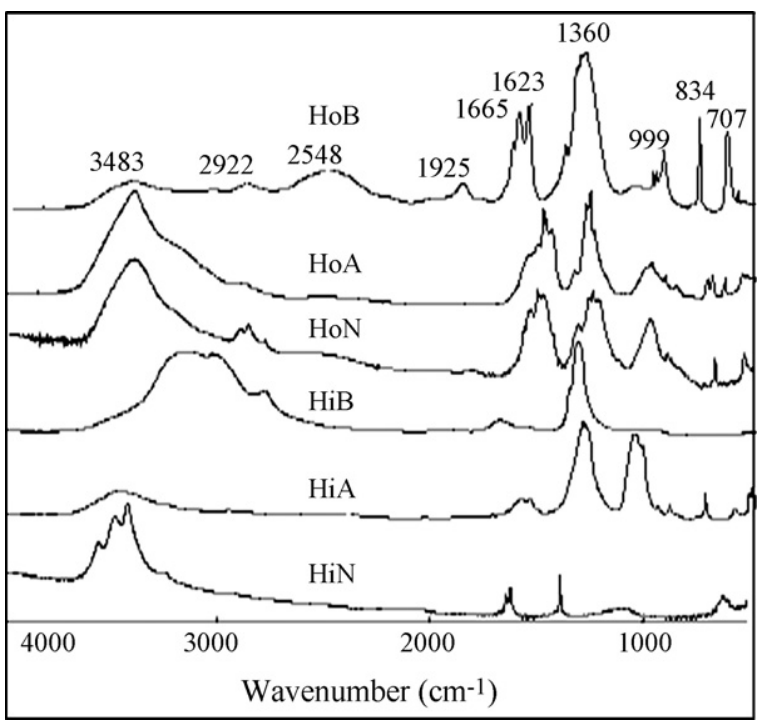

Fig. 4. FTIR spectra of DOM fractions from reuse water of Gaobeidian STP. HoA, hydrophobic acids; HiA, hydrophilic acids; HoB, hydrophobic bases; HiB, hydrophilic bases; HoN, hydrophobic neutrals; HiN, hydrophilic neutrals.

\subsection{Effect of chemical structures on THMFP and HAAFP of DOM fractions}

The FTIR spectra of DOM fractions are shown in Fig. 4. Interpretation of the absorption bands of DOM was done as described in the literature $[10,24,25]$. Three hydrophobic organics were similar in spectra with four distinctive adsorption bands: $1670-1700 \mathrm{~cm}^{-1}$ indicating carboxylate salt $\nu \mathrm{COO}^{-} ; 1600-1650 \mathrm{~cm}^{-1}$ suggesting aromatic skel $\nu \mathrm{C}=\mathrm{C}$ or aldehydate and ketonate groups $\nu \mathrm{C}=0 ; 1400-1450 \mathrm{~cm}^{-1}$ attributed to aliphatic structures and $900-1200 \mathrm{~cm}^{-1}$ largely due to carbohydrates $\nu \mathrm{C}-\mathrm{C}$ or O-alky group $v(\mathrm{C}-\mathrm{O})$. Compared with hydrophobic organics, HiA also had the four adsorption bands but the band corresponding to carboxylate salt was lower than the others; in addition to the distinctive adsorption band at about $1384 \mathrm{~cm}^{-1}$, HiB showed a relatively weak band at $1758 \mathrm{~cm}^{-1}$ corresponding to the ester carbonyl; HiN had quite low peaks, whereas the adsorption bands corresponding to carboxylate salts and carbohydrates were relatively high.

Hydrophobic organics and hydrophilic organics (with the exception of $\mathrm{HiB}$ ) were similar with their FTIR spectra indicating aromatic moieties and carbohydrates. Organic acids, HoA and $\mathrm{HiA}$, showed adsorption bands at $1300-1450 \mathrm{~cm}^{-1}$ indicating aliphatic structures $\nu \mathrm{C}-\mathrm{C}$, whereas HoA exhibited higher contents at $1600-1700 \mathrm{~cm}^{-1}$ indicating aromatic moieties and HiA contained more $v(C-O)$ groups, such as hydroxy acid and O-alky organics. On the other hand, HoA and HiA possessed the highest HAAFP and THMFP, respectively, suggesting that a combination of aromatic moieties and aliphatic structures with $v(\mathrm{C}-\mathrm{O})$ groups contributed largely to the formation of DBPs. Furthermore, HAAFP attributed to aromatic moieties and THMFP depended much on aliphatic structures with $v(\mathrm{C}-\mathrm{O})$ groups. Compared with other fractions, HiB exhibited more aliphatic organics without $v(\mathrm{C}-\mathrm{O})$ groups, thus leading to the lowest DBPFP. HiN contained relatively low aromatic moieties; however, the DBPFP of HiN was higher than organic bases. The reason might lie in the low molecular weight of HiN.

\section{Conclusions}

DOM in effluent from a conventional sewage treatment plant was isolated using RAC technique into six fractions: $\mathrm{HoA}$, HoB, 
HoN, HiA, HiB and HiN. Hydrophobic organics especially hydrophobic acids were found to have higher overall DBPFP and the potential decreased as the sequence of acids, neutrals and bases. DOM-fraction distribution, SUVA, source, molecular weights and chemical structures of DOM fractions were found to influence the formation of DBPs largely.

(1) More than $60 \%$ of DOM from the effluent was hydrophobic organics. In particular, HoA were found to be the most abundant component and HiA were the second most dominant fraction. Organic acids constituted the dominant precursors in the formation of DBPs. SUVA of DOM fractions, especially hydrophobic organics, exhibited a certain linear relationship with the related DBPFP.

(2) Different source of organics led to difference in the formation of DBPs of DOM fractions. Humic acids exhibited higher chlorine reactivity than fulvic acids. Aromatic proteins and soluble microbial products such as protein-like or phenol-like organics produced significant DBPs.

(3) Organic acids, HoA and HiA, exhibited higher molecular weights. Compared with hydrophobic fractions, hydrophilic organics exhibited low molecular weights with the exception of HiA. Small molecules of humic acids exhibited high DBPFP.

(4) Chemical structures greatly influenced the formation of DBPs. A combination of aromatic moieties and aliphatic structures with $v(\mathrm{C}-\mathrm{O})$ groups contributed largely to the formation of DBPs. HAAFP attributed to aromatic moieties and THMFP depended much on aliphatic structures with $v(\mathrm{C}-\mathrm{O})$ groups.

\section{Acknowledgements}

This work was supported by National Natural Science Foundation of P.R. China (50538090) and by the Funds for National High-Tech Research and Development Plan of P.R. China (2007AA06Z338).

\section{References}

[1] D. Abdessemed, G. Nezzal, R.B. Aim, Coagulation-adsorption-ultrafiltration for wastewater treatment and reuse, Desalination 131 (2000) 307-314.

[2] W.Z. Lu, A.Y.T. Leung, A preliminary study on potential of developing shower/laundry wastewater reclamation and reuse system, Chemosphere 52 (2003) 1451-1459.

[3] J.Y. Chu, J.N. Chen, C. Wang, Wastewater reuse potential analysis: implications for China's water resources management, Water Res. 38 (2004) 2746-2756.

[4] M. Gómez, A. de la Rua, G. Garralón, Urban wastewater disinfection by filtration technologies, Desalination 190 (2006) 16-28.
[5] J.M. Zha, Z.J. Wang, Assessing technological feasibility for wastewater reclamation based on early life stage toxicity of Japanese medaka (Oryzias latipes), Agric. Ecosyst. Environ. 107 (2005) 187-198.

[6] C. Trevizo, H.N. Nirmalak, Prediction of microbial toxicity of industrial organic chemicals, Water Sci. Technol. 39 (1999) 63-69.

[7] Z. Chen, C.Y. Yang, J.H. Lu, Factors on the formation of disinfection by-products MX, DCA and TCA by chlorination of fulvic acid from lake sediments, Chemosphere 45 (2001) 379-385.

[8] X. Yang, C. Shang, P. Westerhoff, Factors affecting formation of haloacetonitriles, haloketones, chloropicrin and cyanogen halides during chloramination, Water Res. 41 (2007) 1193-1200.

[9] T. Sirivedhin, K.A. Gray, 2. Comparison of the disinfection by-product formation potentials between a wastewater effluent and surface waters, Water Res. 39 (2005) 1025-1036.

[10] J.A. Leenheer, C. Rostas, L. Barber, Nature and chlorine reactivity of organic constituents from reclaimed water in groundwater, Los Angeles county, California, Environ. Sci. Technol. 35 (2001) 3869-3876.

[11] H.K. Shon, S. Vigneswaran, S.A. Snyder, Effluent organic matter (EfOM) in wastewater: constituents, effects, and treatment, Crit. Rev. Environ. Sci. Technol. 36 (2006) 327-374.

[12] E.C. Wert, F.L. Rosario-Ortiz, D.D. Drury, Formation of oxidation byproducts from ozonation of wastewater, Water Res. 41 (2007) 1481-1490.

[13] A. Imai, T. Fukushima, K. Matsushige, Characterization of dissolved organic matter in effluents from wastewater treatment plants, Water Res. 36 (2002) 859-870.

[14] J.A. Leenheer, Comprehensive approach to preparative isolation and fractionation of dissolved organic carbon from natural waters and wastewaters, Environ. Sci. Technol. 15 (1981) 578-587.

[15] B. Chefetz, P.G. Hatcher, Y. Hadar, Characterization of dissolved organic matter extracted from composted municipal solid waste, Soil Sci. Soc. Am. J. 62 (1998) 326-332.

[16] A. Bruchet, C. Anselme, J.P. Duguet, J. Mallevialle, THM formation potentia and organic content: a new approach in water chlorination chemistry, Environ. Impact Health Effects 6 (1987) 633-647.

[17] E. O'Loughlin, Y.P. Chin, Effect of detector wavelength on the determination of the molecular weight of humic substances by high-pressure size exclusion chromatography, Water Res. 35 (2001) 333-338.

[18] L.S. Wang, H.Y. Hu, C. Wang, Effect of ammonia nitrogen and dissolved organic matter fractions on the genotoxicity of wastewater effluent during chlorine disinfection, Environ. Sci. Technol. 41 (2007) 160-165.

[19] D.A. Reckhow, P.C. Singer, R.L. Malcolm, Chlorination of humic materials: byproduct formation and chemical interpretations, Environ. Sci. Technol. 24 (1990) 1655-1664.

[20] G.V. Korshin, C.W. Li, M.M. Benjamin, The decrease of UV absorbance as an indicator of TOX formation, Water Res. 31 (1997) 946-949.

[21] Y.R. Tan, J.E. Kilduff, M. Kitis, Dissolved organic matter removal and disinfection byproduct formation control using ion exchange, Desalination 176 (2005) 189-200.

[22] M. Kitis, T. Karanfil, A. Wigton, Probing reactivity of dissolved organic matter for disinfection by-product formation using XAD-8 resin adsorption and ultrafiltration fractionation, Water Res. 36 (2002) 3834-3848.

[23] W. Chen, P. Westeroff, J.A. Leenheer, Fluorescence excitation-emission matrix regional integration to quantify spectra for dissolved organic matter, Environ. Sci. Technol. 37 (2003) 5701-5710.

[24] V. Kanokkantapong, T.F. Marhaba, P. Pavasant, Characterization of haloacetic acid precursors in source water, Journal of environmental management 80 (2006) 214-221.

[25] H.C. Kim, M.J. Yu, Characterization of natural organic matter in conventional water treatment processes for selection of treatment processes focused on DBPs control, Water Res. 39 (2005) 4779-4789. 